\title{
Influence of pulmonary ventilation rate and breathing cycle period on the risk of cross-
} infection

\section{Ai, Zhengtao; Hashimoto, Kaho; Melikov, Arsen Krikor}

\section{Published in:}

Indoor Air

Link to article, DOI:

10.1111/ina.12589

Publication date:

2019

Document Version

Peer reviewed version

Link back to DTU Orbit

Citation (APA):

Ai, Z., Hashimoto, K., \& Melikov, A. K. (2019). Influence of pulmonary ventilation rate and breathing cycle period on the risk of cross-infection. Indoor Air, 29(6), 993-1004. https://doi.org/10.1111/ina.12589

\section{General rights}

Copyright and moral rights for the publications made accessible in the public portal are retained by the authors and/or other copyright owners and it is a condition of accessing publications that users recognise and abide by the legal requirements associated with these rights.

- Users may download and print one copy of any publication from the public portal for the purpose of private study or research.

- You may not further distribute the material or use it for any profit-making activity or commercial gain

- You may freely distribute the URL identifying the publication in the public portal

If you believe that this document breaches copyright please contact us providing details, and we will remove access to the work immediately and investigate your claim 
DR. ZHENGTAO Al (Orcid ID : 0000-0003-2635-2170)

Article type : Original Article

Influence of Pulmonary Ventilation Rate and Breathing Cycle Period on the Risk of Cross Infection

Z.T. Ai ${ }^{1, *}$, K. Hashimoto ${ }^{1,2}$, A.K. Melikov ${ }^{1}$

${ }^{1}$ International Centre for Indoor Environment and Energy, Department of Civil Engineering, Technical University of Denmark

${ }^{2}$ Department of Architecture, Faculty of Science and Engineering, Waseda University

*Corresponding email: zheai@byg.dtu.dk; zhengtaoai@hnu.edu.cn

ORCID:

Z.T. Ai: 0000-0003-2635-2170

A.K. Melikov: 0000-0003-0200-6046

This article has been accepted for publication and undergone full peer review but has not been through the copyediting, typesetting, pagination and proofreading process, which may lead to differences between this version and the Version of Record. Please cite this article as doi: 10.1111/ina.12589

This article is protected by copyright. All rights reserved. 


\begin{abstract}
This study examined the characteristics of the exhaled airflow pattern and breathing cycle period of human subjects and evaluated the influence of pulmonary ventilation rate and breathing cycle period on the risk of cross infection. Measurements with five human subjects and a breathing thermal manikin were performed and the peak exhaled airflow velocity from the mouth and the breathing cycle period were measured. Experiments on cross infection between two breathing thermal manikins were then conducted in a fullscale test room, in which the pulmonary ventilation rate and breathing cycle period were varied systematically. Both peak flow velocity and breathing cycle length varied considerably between different subjects. The breathing cycle period in a standing posture was $18.9 \%$ lower than in a sitting posture. The influence of pulmonary ventilation rate and breathing cycle period extended up to a separation distance of $1.0 \mathrm{~m}$ between the two manikins. Increasing the pulmonary ventilation rate of the exposed person greatly increased the risk of cross infection. Decreasing the breathing cycle period from the widely used ' 6 second' value led to a considerable increase in the risk of cross infection. Standing posture resulted in a higher risk of cross infection than sitting posture.
\end{abstract}

Keywords: human exhalation; pulmonary ventilation rate; breathing cycle period; airborne transmission; human exposure; chamber experiment

Practical implications: The findings of the present study have two practical implications. The first is that the exhaled airflow pattern and breathing cycle period of manikins should be selected to be similar to those of the target subjects. The second is that different control measures for short-range cross infection (within $1.0 \mathrm{~m}$ in separation distance between occupants) should be taken according to the breathing characteristics of the target subjects.

This article is protected by copyright. All rights reserved. 


\section{Introduction}

The frequent outbreaks of respiratory infectious diseases worldwide result in massive sickness absence, huge economic loss and millions of deaths per year. ${ }^{1}$ Airborne cross infection has therefore become an important research topic. Human exhalation and inhalation play important roles in the whole process of airborne cross infection, namely disseminating and receiving infectious viruses through exhalation and inhalation, respectively. ${ }^{2}$ Improving our understanding of the characteristics of human

respiration and its influence on the risk of cross infection is thus of fundamental importance.

The thermofluid characteristics of human exhalation and inhalation generally consist of five important aspects: geometry of the mouth and nose openings, ${ }^{3-7,8}$ direction of exhaled airflow jets, ${ }^{3-7,8}$ temperature of the exhaled air, ${ }^{9}$ breathing mode, pulmonary ventilation rate and breathing cycle period (frequency). The present study focused only on the influence of the pulmonary ventilation rate and breathing cycle period. Assuming identical other boundary conditions, pulmonary ventilation rate determines the velocity of the exhaled flow and thus determines the length of the exhaled flow jets. In past studies ${ }^{3-7,10-22}$ of airborne cross infection during light activities carried out in a sitting and standing posture, the pulmonary ventilation rate was defined in a wide range, from 6.0 to $10.0 \mathrm{~L} / \mathrm{min}$. A few studies using thermal manikins reported the velocity of the exhaled airflow for normal breathing: $3.0 \mathrm{~m} / \mathrm{s}$ (at peak) from the nose, ${ }^{23} 2.0-3.0 \mathrm{~m} / \mathrm{s}$ (at peak) from the mouth, ${ }^{24} 4.74 \mathrm{~m} / \mathrm{s}$ (at peak) from the mouth $^{6}$ and $2.67 \mathrm{~m} / \mathrm{s}$ (averaged) from the mouth. ${ }^{25}$ These velocities were in general higher than those measured in human subject studies, where the peak flow velocity during normal breathing was reported to be approximately $1-2 \mathrm{~m} / \mathrm{s}^{26-29}$ The differences in exhaled airflow velocity defined and reported in past studies suggest that there may be considerable variation between different groups of people. In previous studies using breathing thermal manikins, a

This article is protected by copyright. All rights reserved. 
breathing cycle period of $6 \mathrm{~s}$ was usually assumed for a pulmonary ventilation rate of 6.0 $\mathrm{L} / \mathrm{min}$, and $4 \mathrm{~s}$ for $10.0 \mathrm{~L} / \mathrm{min}$; the breathing cycle of 2.5 second inhalation, 2.5 second exhalation and 1 second pause was most widely used, ${ }^{11-12,30-31}$ although many studies used a cycle without a pause between exhalation and inhalation. ${ }^{10,23,32}$

It is important to define and use the concept of a 'standard person' in studies of cross infection when comparing the results of different studies. In general, the pulmonary ventilation rate and breathing cycle period of 'standard persons' were used in past studies ${ }^{3-}$ 7,10-22,30-31,33 of airborne cross infection. However, such a 'standard person' was established based on a certain group of people, mostly adults engaged in office work. Both pulmonary ventilation rate and breathing cycle period depend on many physiological factors, such as body size, metabolic rate (activity level), gender and age. ${ }^{33} \mathrm{~A}$ 'standard person' can be defined for a certain group of people with similar physiological characteristics, but not for different groups of people. For examples, there would be differences in pulmonary ventilation rate $^{33}$ between office workers and audiences in sport stadiums and differences in breathing cycle period between adults and children. ${ }^{34-37}$ In order to more precisely formulate measures for controlling the risk of cross infection for different groups of people, it is necessary to identify the influence of the pulmonary ventilation rate and the breathing cycle period.

In order to study the influence of pulmonary ventilation rate and breathing cycle period, two experiments were performed in the present study. Five human subjects were recruited and a breathing thermal manikin was used for measurements of the exhaled airflow velocity around the mouth, both while standing and while sitting. The time series of velocities were then analysed to determine the breathing cycle period. The human subject (including one manikin) measurements were used to preliminarily investigate the basic characteristics of 
peak exhaled airflow velocity and breathing cycle period, which, together with the published data reviewed above, were then used to guide the design of experiments on airborne crossinfection by suggesting the investigated ranges of the two parameters. The experiments on cross infection were conducted in a full-scale test room with mixing ventilation, and two manikins were used, one to simulate an infected person and the other to simulate an exposed person. The influence of pulmonary ventilation rate and breathing cycle period on the risk of cross infection was then quantified.

\section{Experimental methods}

Two separate experiments were conducted in this study: first, measurement of the exhaled airflow from the mouth of human subjects and from a breathing thermal manikin and second, measurement of airborne cross infection between two breathing thermal manikins.

\subsection{Measurement of exhaled flow from the mouth}

\subsubsection{Test room and air distribution}

Measurements of the magnitude and distribution of exhaled airflow velocity at the mouth of human subjects was performed in a full-scale test room with dimensions of $4.4 \mathrm{~m} \times 4.7 \mathrm{~m}$ $\times 2.6 \mathrm{~m}$ (see Figure 1 (a)). The room was located in a large laboratory hall, where the air temperature was controlled by a separate ventilation system to be close to the average air temperature of the test room. Mixing air distribution (MV) was created in the test room using a square supply air diffuser with a perforated face plate. The diffuser was located at the centre of the ceiling and an exhaust diffuser was located in the corner of the ceiling. During the experiments, $100 \%$ outdoor air was supplied to the room. The number of air changes per hour $(\mathrm{ACH})$ in the test room was maintained at $4 \mathrm{~h}^{-1}$. The background air velocity in the test room without the presence of human subject and thermal manikin was less than $0.2 \mathrm{~m} / \mathrm{s}$. The

This article is protected by copyright. All rights reserved. 
supply air temperature was $23 \pm 0.5$. The relative humidity of the room air was not controlled but was measured to be approximately 30-40\%. Six fluorescent light fixtures of 6 $\mathrm{W}$ each were in operation, mounted on the ceiling.
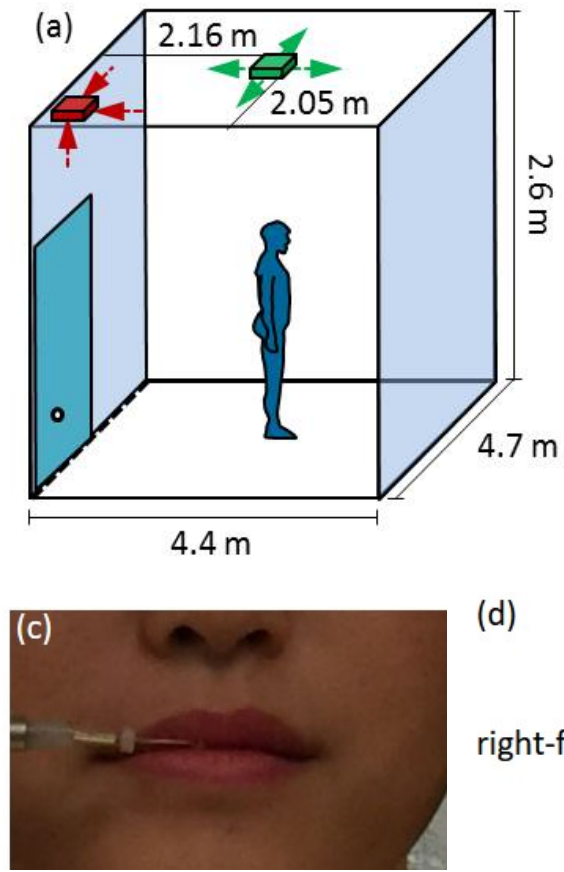

(d)
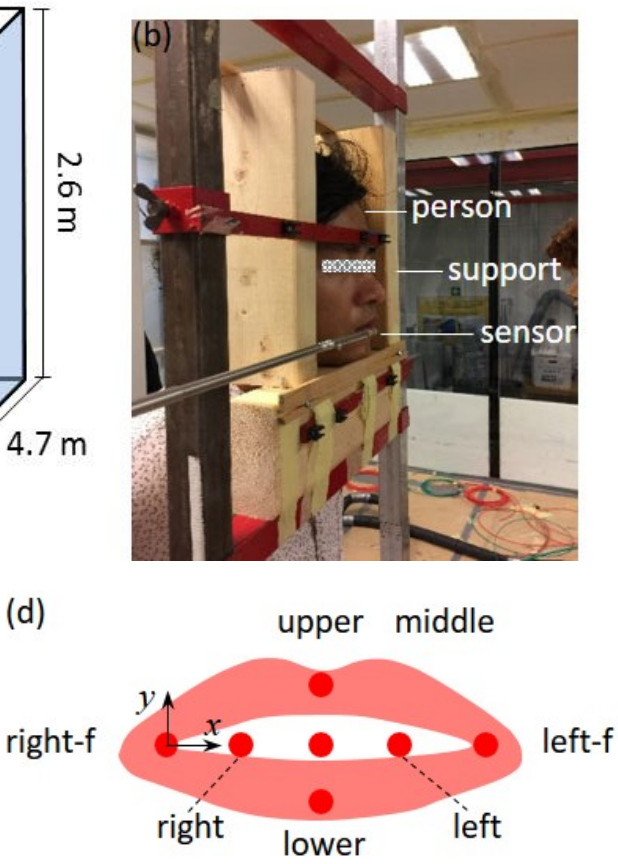

Figure 1 Experimental setup for measuring the velocity of the airflows exhaled by human subjects: (a) a schematic view of test room and the location of the human subjects (note that both standing and sitting postures were measured), (b) an adjustable wooden box supporting and fixing the head of a subject, (c) a front view of the mouth and an anemometer sensor and (d) 2D locations of measurement in front of the mouth; note that only one anemometer sensor was used and measurements at different locations around the mouth were conducted at different times.

\subsubsection{Human subjects and thermal manikin}

A total of five human subjects were recruited for the measurements. The ages of the five human subjects ranged from 22 to 70 years old; their body mass ranged from 50 to $75 \mathrm{Kg}$, and their heights from 158 to $175 \mathrm{~cm}$. Their body surface areas were from 1.48 to $1.88 \mathrm{~m}^{2}$. The detailed information of the five human subjects is listed in Table 1. For comparison purposes, the same measurements were conducted for a breathing thermal manikin. The manikin was designed to be geometrically similar to the shape and size of an average adult 
woman of $1.7 \mathrm{~m}$ in height, with a body surface area of approximately $1.57 \mathrm{~m}^{2}$. It consisted of a number of body segments that could be separately heated. The surface temperature and the heat supplied to each of the body segments were controlled by a computer program. In this study, the surface temperature of the thermal manikin was controlled to be close to the skin temperature of a person in a state of thermal comfort. The sensible heat loss of the manikin was $80 \mathrm{~W}$. The clothes worn by the manikin were typical summer suits including a shorthaired wig, T-shirt, trousers, underwear, ankle-length light socks and light shoes, which provided 0.5 Clo of thermal insulation. The manikin was connected to an artificial lung ${ }^{38}$ to simulate human breathing in a sinusoidal flow sequence of exhalation, inhalation and pause. The exhaled air was not humidified ${ }^{39}$ but was heated to 34.7 . The use of this temperature compensated for the lack of humidification. The nostrils were circular openings and the mouth an ellipsoidal opening. The two jets from the nostrils were angled $45^{\circ}$ downwards from the horizontal plane and $30^{\circ}$ from each other. ${ }^{40}$ Each nostril had a cross-sectional area of $38.5 \mathrm{~mm}^{2}$ and that of the mouth was $158 \mathrm{~mm}^{2}{ }^{41}$

Table 1 Basic information of the five human subjects.

\begin{tabular}{lllll}
\hline Subject & Age & Weight $(\mathrm{Kg})$ & Height $(\mathrm{cm})$ & BSA $\left(\mathrm{m}^{2}\right)$ \\
\hline A & 70 & 75 & 172 & 1.88 \\
B & 43 & 48 & 160 & 1.47 \\
C & 32 & 67 & 175 & 1.81 \\
D & 31 & 64 & 173 & 1.76 \\
E & 22 & 50 & 158 & 1.48 \\
\hline
\end{tabular}

\subsubsection{Experimental conditions}

The imposed breathing mode for the human subjects and the manikin were inhalation through the nose and exhalation through the mouth. Note that in this first experiment, the manikin was used to compare with the human subjects, and it was therefore not relevant to distinguish source or exposed manikin. The human subjects were instructed to breath

This article is protected by copyright. All rights reserved. 
naturally and the extent to which their mouths were open was optional. They were asked to practice the aforementioned breathing mode before the measurements. For each human subject and the breathing thermal manikin, two experimental conditions, a standing and a sitting posture, were studied. The exhaled airflow velocity close to the mouth was measured. The measurement locations in front of the mouth are shown in Figure 1 (c)-(d). These measurements were conducted on two vertical planes, which were $1 \mathrm{~cm}$ and $3 \mathrm{~cm}$ away from the mouth. Note that the central five red points (right-f, right, middle, left and left-f) shown in Figure 1 (d) indicate the locations where the maximum velocity on those vertical lines occurred. For the thermal manikin, these five measurement locations were on the horizontal plane across the centre of the mouth. For the human subjects, however, they were not uniformly located and most of them deviated from the horizontal plane across the centre of the mouth. This exemplifies the diversity and complexity of the human breathing pattern.

\subsubsection{Instrumentation}

For both standing and sitting postures, the head of each human subject was supported and effectively fixed in place with the help of an adjustable wooden box (see Figure 1 (b)), in order to reduce movement during the measurements. A coordinate system was defined from the right corner of the mouth (Figure $1(\mathrm{~d})$ ). The airflow velocity was measured using a Swema 3000 omnidirectional anemometer (Swema AB, Pepparvågen 27, SE-123 56 FARSTA, Sweden), which had a measurement range of 0-10 m/s and a sampling frequency of $10 \mathrm{~Hz}$. The anemometer was calibrated by the manufacturer before performing the present experiments. Any effect on accuracy of the difference between the temperature and humidity maintained during the calibration and during the measurements was compensated. The measurement uncertainty was $0.05 \mathrm{~m} / \mathrm{s}$ in the range $0.1-1.1 \mathrm{~m} / \mathrm{s}$ and $4.5 \%$ of read value in the range $1.1-10 \mathrm{~m} / \mathrm{s}$. The probe was mounted on a traversing system and moved accurately $( \pm$ 
$0.001 \mathrm{~m}$ ) in three directions. The control and display of the measurements were carried out by a computer program. At each location, the measurement continued for 3 minutes during which 1800 data points were obtained. According to the results shown in Section 3.1.3, the breathing cycle period of the five human subjects ranged from $2.1 \mathrm{~s}$ to $4.4 \mathrm{~s}$, so the measurement period of 3 minutes comprised approximately 41-86 breathing cycles. Previous studies $^{24,42}$ have reported that the breathing pattern of a person was relatively stable and reproducible under similar steady-state conditions, although differences could be observed between repeated measurements. Two repeated measurements with each human subject confirmed this finding and the results of one set of measurements were eventually used in the present study.

\subsubsection{Data analyses}

Based on the time series of exhaled airflow velocity measured for the human subjects, all peak values during exhalation were identified (see Figure 2 for example). The peak values at each measurement location were then used to calculate the time-averaged peak airflow velocity and its standard deviation, and the breathing cycle period. The breathing cycle period was estimated by averaging all time periods between consecutive peak values.

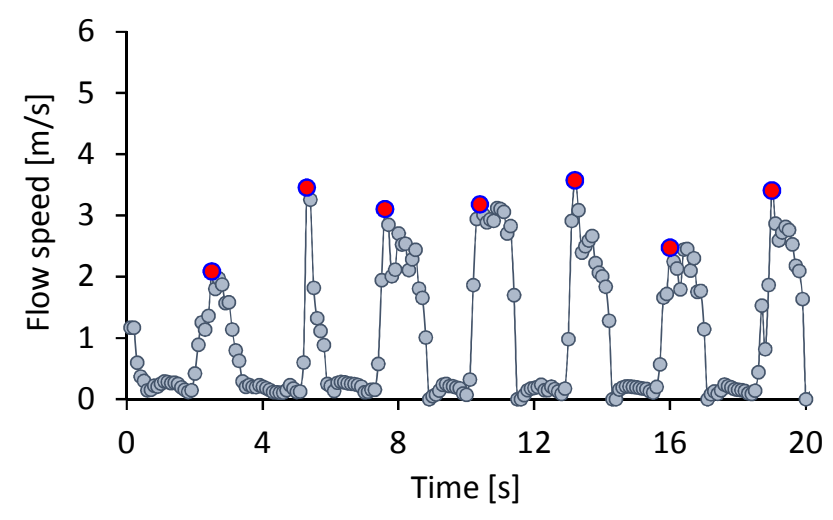

Figure 2 An example of the evolution of exhaled flow velocity over time at a specific measuring location of one of the human subjects; the peak values (red dots) of flow speed are highlighted.

This article is protected by copyright. All rights reserved. 


\subsection{Measurement of cross infection between two breathing thermal manikins}

\subsubsection{Test room, air distribution and breathing thermal manikins}

The test room, air distribution, $\mathrm{ACH}$, temperature and relative humidity of room air were the same as those described in Section 2.1.1. The infected and exposed standing persons were simulated using two breathing thermal manikins (see Figure 3 (b)). Detailed information on the thermal manikins is provided in Section 2.1.2. The breathing mode of the source manikin was inhalation through the nose and exhalation through the mouth and that of the exposed manikin was inhalation through the mouth and exhalation through the nose. The breathing phase of the two manikins was not controlled. The mouths of the two face-to-face manikins were nearly at the same height above floor.
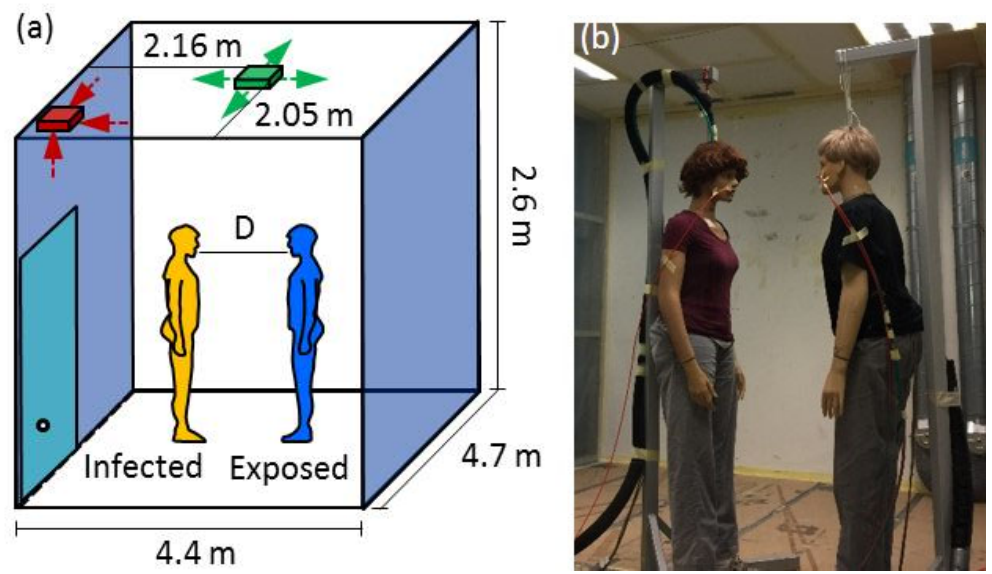

Figure 3 Setup of the test room and photo of the two manikins; 'D' denotes the separation distance between two mouths.

This article is protected by copyright. All rights reserved. 
Table 2 A list of experimental conditions; the full set of separation distance includes 0.35 , $0.5,0.6,0.8,1.0,1.2,1.4$ and $1.6 \mathrm{~m}$; the three numbers in the parentheses in the column 'Breathing cycle period refer to the periods of inhalation, exhalation and pause within a breathing cycle, respectively.

\begin{tabular}{lllll}
\hline $\begin{array}{l}\text { Cases Pulmonary ventilation } \\
\text { rate-infected (L/min) }\end{array}$ & $\begin{array}{l}\text { Pulmonary ventilation } \\
\text { rate -exposed (L/min) }\end{array}$ & $\begin{array}{l}\text { Breathing cycle } \\
\text { period }(\mathrm{s})\end{array}$ & $\begin{array}{l}\text { Separation } \\
\text { distance }(\mathrm{m})\end{array}$ \\
\hline 1 & 6 & 6 & $6(2.5-2.5-1.0)$ & $\begin{array}{l}\text { Full set } 0.35- \\
1.6\end{array}$ \\
2 & 9 & 6 & $6(2.5-2.5-1.0)$ & $\begin{array}{l}\text { Full set } 0.35- \\
1.6\end{array}$ \\
3 & 6 & & $6(2.5-2.5-1.0)$ & $\begin{array}{l}\text { Full set } 0.35- \\
1.6\end{array}$ \\
4 & 9 & 9 & $6(2.5-2.5-1.0)$ & $\begin{array}{l}\text { Full set } 0.35- \\
1.6\end{array}$ \\
5 & 6 & 9 & $4.8(2.0-2.0-0.8)$ & $\begin{array}{l}\text { Full set } 0.35- \\
1.6\end{array}$ \\
6 & 6 & 6 & $3.6(1.5-1.5-0.6)$ & $\begin{array}{l}\text { Full set } 0.35- \\
1.6\end{array}$ \\
7 & 6 & 6 & $2.4(1.0-1.0-0.4)$ & $\begin{array}{l}\text { Full set } 0.35- \\
1.6\end{array}$ \\
\hline
\end{tabular}

\subsubsection{Experimental conditions}

The manikins were placed at the centre plane of the test room, as shown in Figure 3. The source manikin on the left side of the figures was located $1.1 \mathrm{~m}$ away from the wall behind it. The independent variables investigated in this study were: pulmonary ventilation rate, breathing cycle period, and the separation distance between the two manikins. The detailed experimental cases and conditions are listed in Table 2. The pulmonary ventilation rate and breathing cycle period used in Case 1 were those that have been widely used in previous studies $^{7,12,17,18,20,22}$ to represent a light activity level, which was therefore taken as the reference case. Cases 1-4 were designed to examine the influence of pulmonary ventilation rate, while in Cases 1, 5-7 the influence of breathing cycle period was examined.

For each case, eight different separation distances, from 0.35 to $1.6 \mathrm{~m}$, were investigated.

This article is protected by copyright. All rights reserved. 


\subsubsection{Measured parameters and instrumentation}

Tracer gas $\left(\mathrm{N}_{2} \mathrm{O}\right.$, nitrous oxide) was used to simulate the virus-containing droplet nuclei in the exhaled flow from the source manikin. It was dosed directly into the exhaled airflow of the source manikin, inside the artificial lung, which was external to the manikin. The dosing rates were 0.4 and $0.6 \mathrm{~L} / \mathrm{min}$ for the pulmonary ventilation rates of 6 and $9 \mathrm{~L} / \mathrm{min}$ respectively, which approximated the component of $\mathrm{CO}_{2}$ in exhalation. In order to maintain a constant total exhalation airflow rate, the air supplied from the lungs was decreased by the same amount $(0.4$ or $0.6 \mathrm{~L} / \mathrm{min})$. The air exhaled by the exposed manikin as outdoor air and thus contained no tracer gas, to simulate the retention of airborne droplet nuclei in human breathing passages and lungs. Two instruments were used to measure the $\mathrm{N}_{2} \mathrm{O}$ concentration, a Fast Concentration Meter (FCM 41) and an INNOVA Multi-gas Sampler and Monitor (1312). The FCM used a non-dispersive infrared absorption (NDIR) method, ${ }^{43,44}$ and had a sampling rate of $4 \mathrm{~Hz}$ and a time constant of $0.8 \mathrm{~s}$. The resolution of the FCM was $1.0 \mathrm{ppm}$ and the expanded uncertainty was $\pm 20.0 \mathrm{ppm}$ (95\% confidence level). The INNOVA instrument (up to six channels) used a photoacoustic principle. When 2 channels were used simultaneously, the sampling rate was $80 \mathrm{~s}$ per set of data. The expanded uncertainty of the INNOVA analyser was $3 \%$ of the reading (95\% confidence level).

Continuous tracer gas measurements were performed at the mouth (namely, inhalation) of the exposed manikin and at the exhaust outlet of the ventilation system. The location of the measuring point at the mouth was placed centrally between the lips and at a distance of 0.005 $\mathrm{m}$ from the surfaces. The tracer gas concentration measured at this location was assumed to be the concentration in the inhaled air. ${ }^{38}$ Tracer gas dosing started after the indoor airflow conditions, i.e. air velocity and temperature, had reached steady-state conditions and ended 40 min after the steady-state condition of concentration had been reached. Tracer gas

This article is protected by copyright. All rights reserved. 
sampling was conducted immediately after the start of dosing. The FCM and INNOVA were cross-calibrated before the experiments. The FCM monitors were calibrated every measuring day both before and after the measurements.

\subsubsection{Data analyses}

The INNOVA data were used directly in further analysis. The FCM data were corrected for the time required for the $\mathrm{N}_{2} \mathrm{O}$ samples to travel in the sampling tube from the sampling location to the FCM monitors. ${ }^{43}$ These time-series of concentrations were divided into two parts, before and under steady-state conditions, in the data analysis. For the data under steady-state conditions, time-averaged mean values were calculated.

The risk of cross infection in steady-state conditions was indicated by the parameter exposure index $(\varepsilon)$, which has been widely used in past studies. ${ }^{3-6,10,12,19,45-50}$

$$
\overline{\varepsilon(t)}=\frac{\overline{\left[C_{\text {ln }}(t)-C_{\text {supply }}(t)\right]}}{\left[C_{\text {exhaust }}(t)-C_{\text {supply }}(t)\right]}
$$

where $C_{i n}$ is the concentration inhaled by the exposed person; $C_{\text {supply }}$ and $C_{\text {exhaust }}$ are the pollutant concentration at the ventilation supply and exhaust, respectively; the overhead bar indicates averaging during the time period $t$ under steady-state conditions. In this study, the

tracer gas $\left(\mathrm{N}_{2} \mathrm{O}\right)$ concentration in the $100 \%$ outdoor ventilation supply air $\left(C_{\text {supply }}\right)$ was assumed to be zero.

\section{Results and analysis}

\subsection{Characteristics of exhaled flows from the mouth}

\subsubsection{General characteristics}

Figure 4 shows the evolution of airflow velocity at the middle of the mouth $(1 \mathrm{~cm}$ away from the mouth) of human subjects and thermal manikin while standing. This figure is This article is protected by copyright. All rights reserved. 
intended to demonstrate some general characteristics of human exhalation from the mouth. As an omnidirectional anemometer cannot detect the airflow direction, no negative values of airflow velocity appear in the results. For most conditions, the airflow velocity during inhalation was not zero, because of the combined effect of the inhaled flow through the nose and the upward thermal plume around the body. Exhalation was unstable in terms of both flow velocity and breathing cycle period, even though the measurements were conducted under steady-state conditions. Even for a given subject, the peak airflow velocity varied considerably. For some subjects, such as Subject E, there was sometimes no obvious and regular breathing cycle period. For most subjects, the exhaled airflow velocity did not follow a sinusoidal pattern. There were obvious differences in the exhalation pattern between human subjects and the thermal manikin that was used as a 'standard person', in terms of both peak airflow velocity and breathing cycle period. Similar differences were reported by Xu et $\mathrm{al}^{24}$, who explained that the use of a circular tube in their manikin's mouth to deliver the exhaled air oversimplified the shape of the breathing passage of a human subject and resulted in higher exhaled airflow velocities. These observations suggest the necessity of exploring the influence of the variation of human exhalation on the risk of cross infection.

This article is protected by copyright. All rights reserved. 

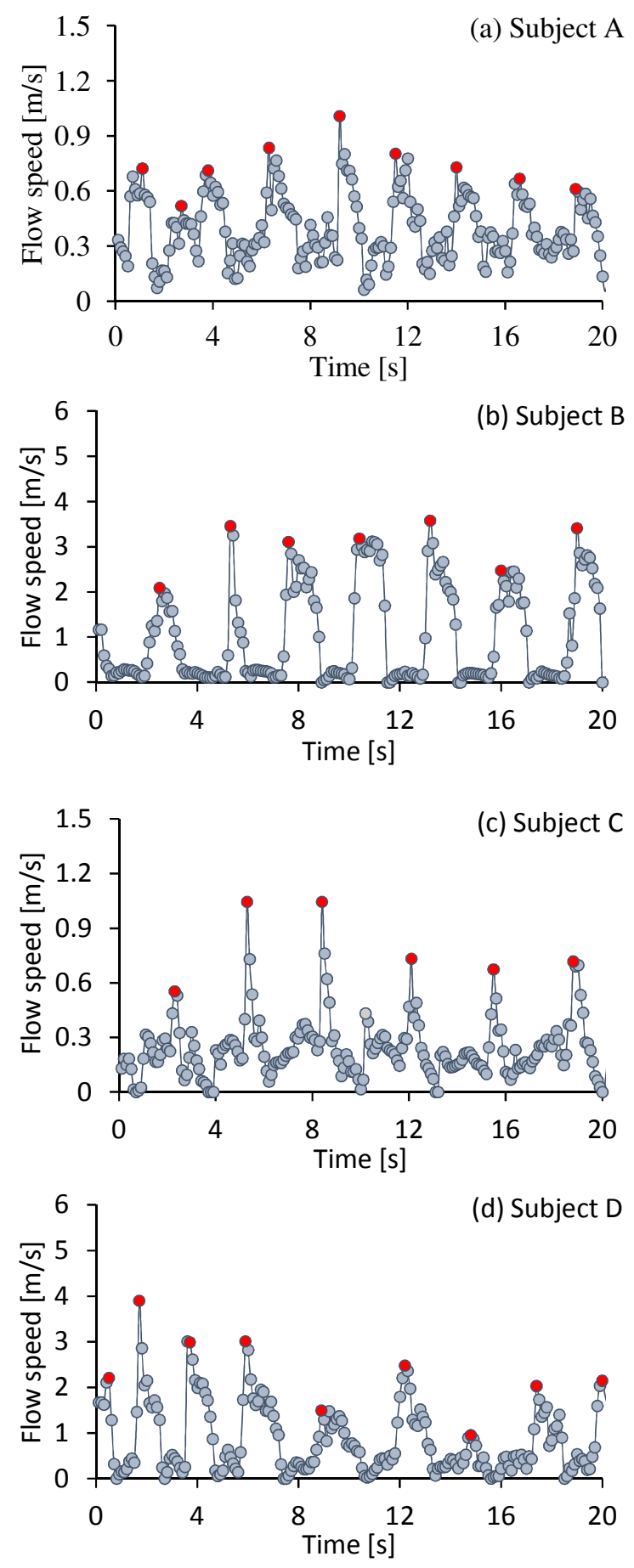

This article is protected by copyright. All rights reserved. 

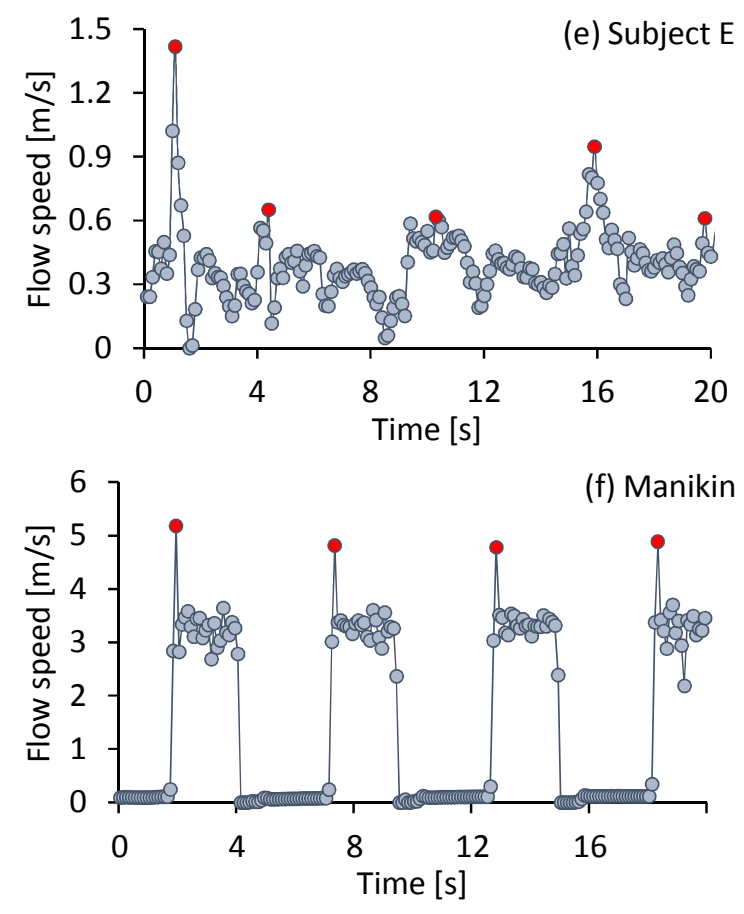

Figure 4 Evolution of airflow velocity at the middle of the mouth $(1 \mathrm{~cm}$ away from the mouth) of human subjects and a thermal manikin while standing.

\subsubsection{Peak exhaled airflow velocity}

Figure 5 shows the average peak exhaled airflow velocity from the mouth of human subjects in standing and sitting postures. For a given human subject, the exhaled airflow was not uniformly and symmetrically distributed at the mouth, and the variations in airflow speed across the mouth were considerable. For most subjects, the highest exhaled airflow velocities were found at either the right or left side of the mouth, which is contrary to the common assumption that the highest velocity occurs at the middle of the mouth. For a given human subject, the distribution of exhaled airflows at the mouth had in general the same characteristics for both standing and sitting postures. For different subjects the distribution and the average peak exhaled airflow velocity differed considerably. For some subjects (e.g., A and B), the average peak velocity at some measurement locations in front of the mouth was about $3 \mathrm{~m} / \mathrm{s}$. The average peak velocities at all the measurement locations varied from 0.61 to $1.6 \mathrm{~m} / \mathrm{s}$ while standing and from 0.64 to $1.5 \mathrm{~m} / \mathrm{s}$ while sitting, and these values are in

This article is protected by copyright. All rights reserved. 
agreement with the results of human subject measurements reported in previous studies (1-2 $\mathrm{m} / \mathrm{s}),{ }^{24,26,28,29}$ but much smaller than those defined for breathing thermal manikins (mostly 2-3 $\mathrm{m} / \mathrm{s}) .^{24,25}$
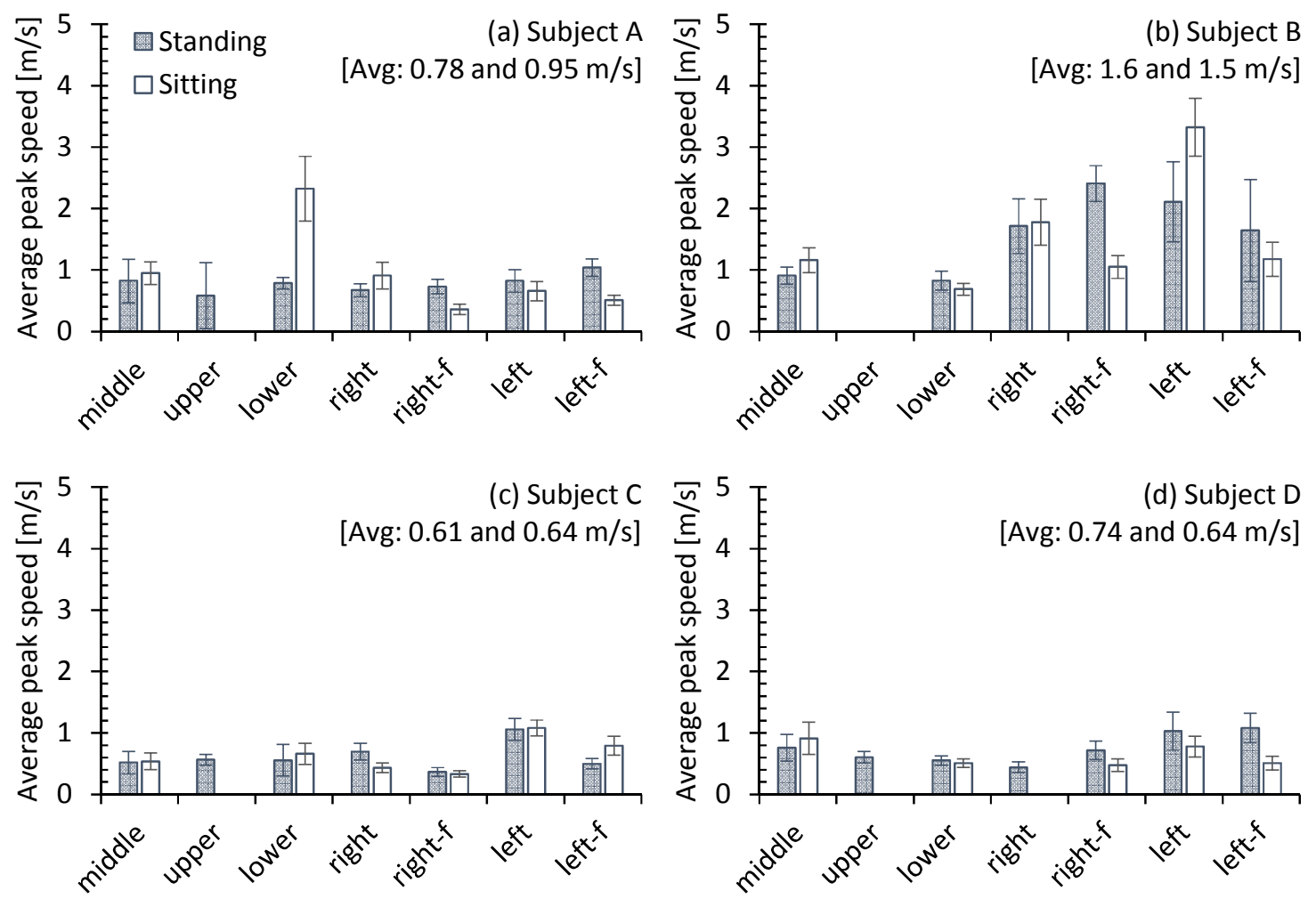

This article is protected by copyright. All rights reserved. 


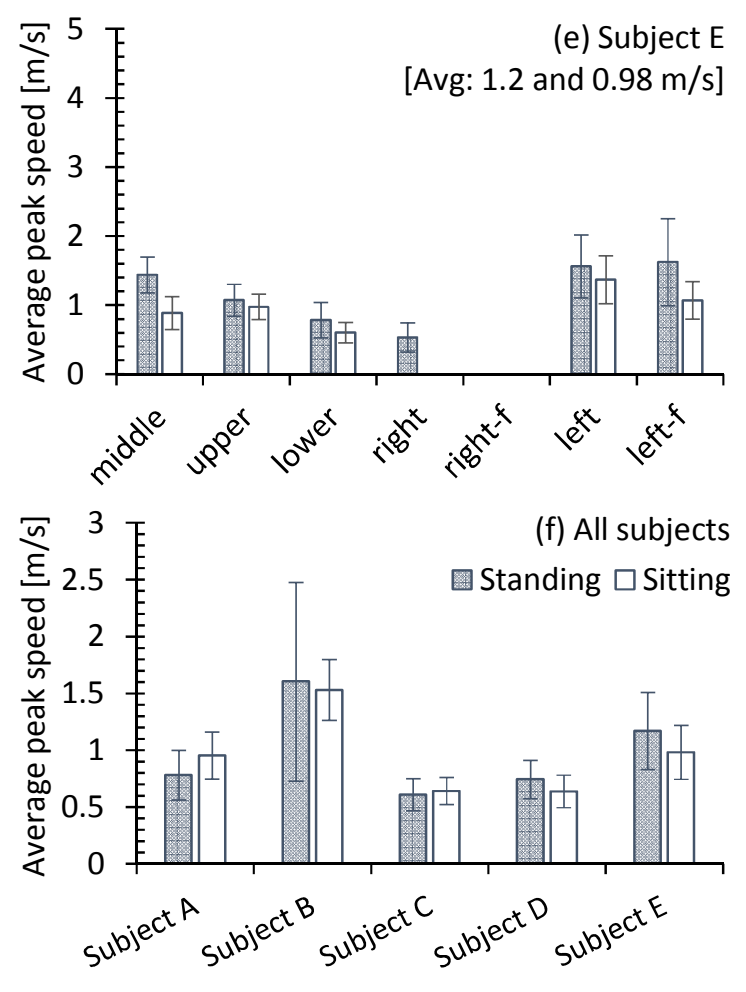

Figure 5 Average peak exhaled airflow velocity at the mouth of human subjects in both standing and sitting postures (some data are missing when there were no clear and regular breathing cycles; this applies to subsequent figures).

Figure 6 shows a comparison of peak exhaled airflow velocity for human subjects measured at $1 \mathrm{~cm}$ and $3 \mathrm{~cm}$ away from mouth. It can be seen that, from $1 \mathrm{~cm}$ to $3 \mathrm{~cm}$, the flow speed decreased by $37.1 \%$ and $31.5 \%$ for standing and sitting postures, respectively. The rapid attenuation of exhaled airflow velocity at an increasing distance from the mouth has been reported in previous studies: Tang et $\mathrm{al}^{28}$ used a Schlieren photographic technique to visualize human exhalation and found that the exhaled airflow could reach up to $0.8 \mathrm{~m}$, while $\mathrm{Xu}$ et $\mathrm{al}^{24}$ used an anemometer to measure the peak exhaled airflow velocity and observed that the reach was only $0.3 \mathrm{~m}$ for a large percentage of subjects.

This article is protected by copyright. All rights reserved. 

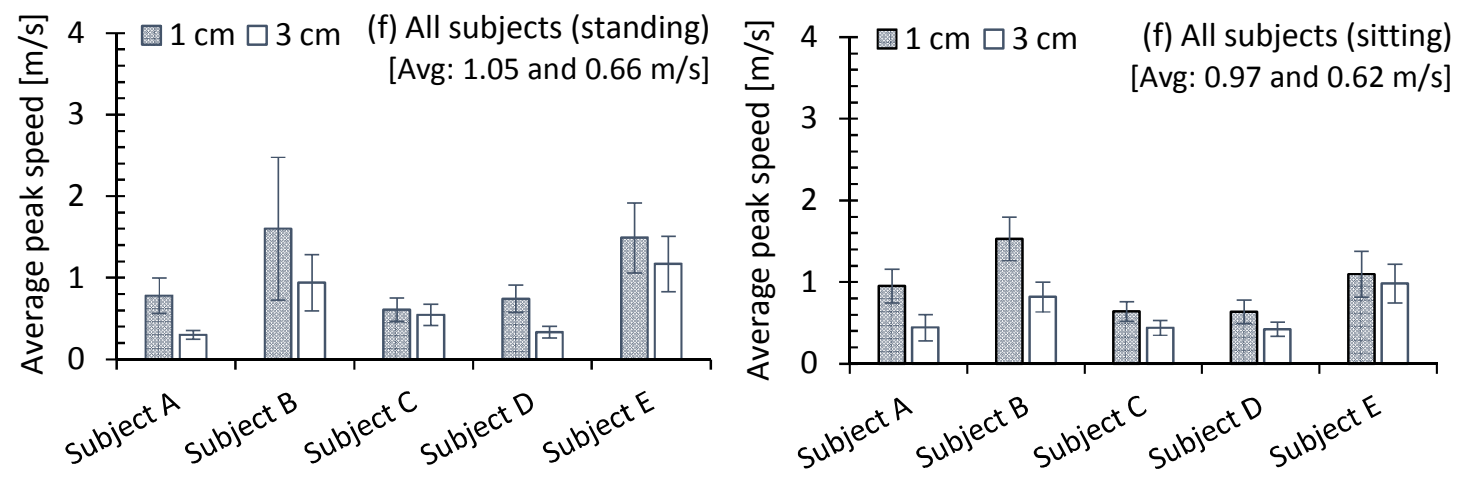

Figure 6 Average peak exhaled airflow velocity from the mouth of human subjects measured at $1 \mathrm{~cm}$ and $3 \mathrm{~cm}$ away from the mouth.

\subsubsection{Breathing cycle period}

Figure 7 shows the breathing cycle period for human subjects in both standing and sitting postures. For a given human subject, as expected, the breathing cycle period calculated on the basis of the peak velocities sampled at different locations around the mouth were relatively close to each other, which supports the reliability and accuracy of the velocity measurements. The difference in breathing cycle period between different locations should be attributed to the instability and fluctuation of respiration over time (see Section 3.1.1), remembering that only one anemometer was used and measurements at different locations around the mouth were conducted at different times. For all human subjects, a standing posture resulted in a shorter breathing cycle period than was observed for a sitting posture, and the relative difference was, on average, $18.9 \%$. The breathing cycle period for different subjects differed considerably. The average breathing cycle period varied from $2.1 \mathrm{~s}$ to $3.5 \mathrm{~s}$ while standing and from $2.7 \mathrm{~s}$ to $4.4 \mathrm{~s}$ while sitting, and these values are in agreement with those reported by Gupta et al. ${ }^{8}(2-8 \mathrm{~s})$.

This article is protected by copyright. All rights reserved. 

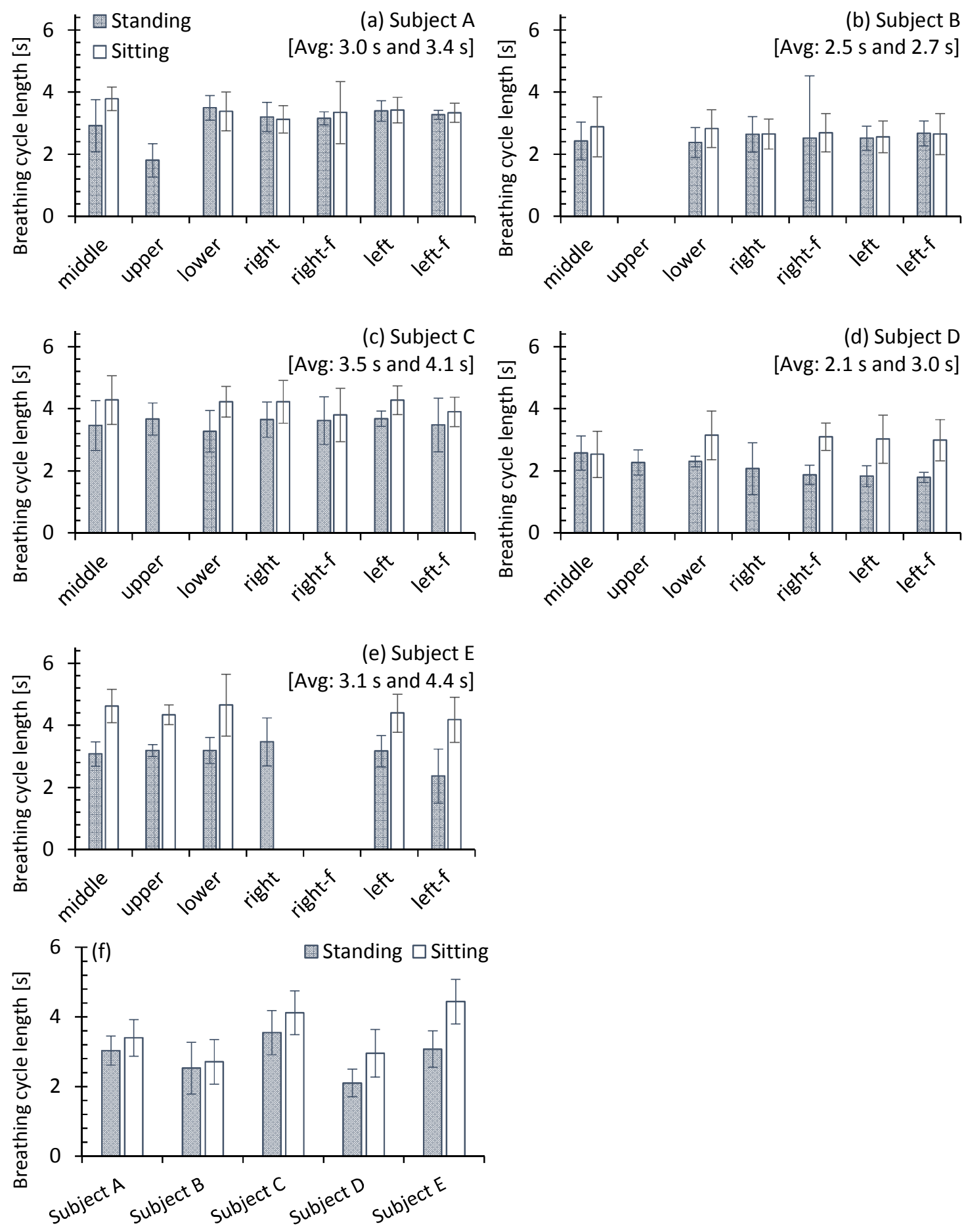

Figure 7 Breathing cycle period for mouth respiration for human subjects in both standing and sitting postures.

This article is protected by copyright. All rights reserved. 


\subsection{Influence of exhaled flow characteristics on airborne transmission}

\subsubsection{Influence of pulmonary ventilation rate}

Figure 8 shows the influence of the pulmonary ventilation rate of infected and exposed persons on the exposure index of the exposed person. The pulmonary ventilation rate had a considerable influence on the exposure index when the separation distance between the infected and the exposed person was less than $1.0 \mathrm{~m}$.

Compared to the case of 6-6 L/min, increasing only the pulmonary ventilation rate of the infected person $(9-6 \mathrm{~L} / \mathrm{min})$ considerably decreased the exposure index at the shortest separation distance $(0.35 \mathrm{~m})$ but increased the exposure index at distances greater than $0.5 \mathrm{~m}$. This may be explained by the two main characteristics of a higher pulmonary ventilation rate: a higher exhaled airflow velocity (the velocity effect) and a larger volume of exhaled flow (concentration effect). When the separation distance was short, the exhaled airflow velocity had a dominant effect on the exposure index. A higher exhaled airflow velocity for the infected person means a shorter period of contact between the exposed person and the exhaled airflow from the infected person. However, when the distance is long, the larger volume of exhaled flow plays a more important role, as it results in a slower dilution by surrounding air and thus a higher exposure index.

Compared to the case 6-6 L/min, increasing the pulmonary ventilation rate of the exposed person $(6-9 \mathrm{~L} / \mathrm{min})$ greatly increased the exposure index at short separation distances $(0.35$, 0.5 and $0.6 \mathrm{~m}$ ). Such a large increase was probably due to a stronger penetration of the exhaled airflow from the infected person to the breathing zone of the exposed person (penetration effect). The penetration effect is discussed in detail in Section 4.

This article is protected by copyright. All rights reserved. 
Compared to the case 6-6 L/min, increasing the pulmonary ventilation rate of both the infected and the exposed persons $(9-9 \mathrm{~L} / \mathrm{min})$ resulted in an increase of the exposure index at all separation distances below $1.0 \mathrm{~m}$. The reasons are similar to those stated in the above two points, namely the combination of the velocity effect and the penetration effect at $0.35 \mathrm{~m}$ and the combination of the concentration effect and the penetration effect at $0.5-0.8 \mathrm{~m}$.
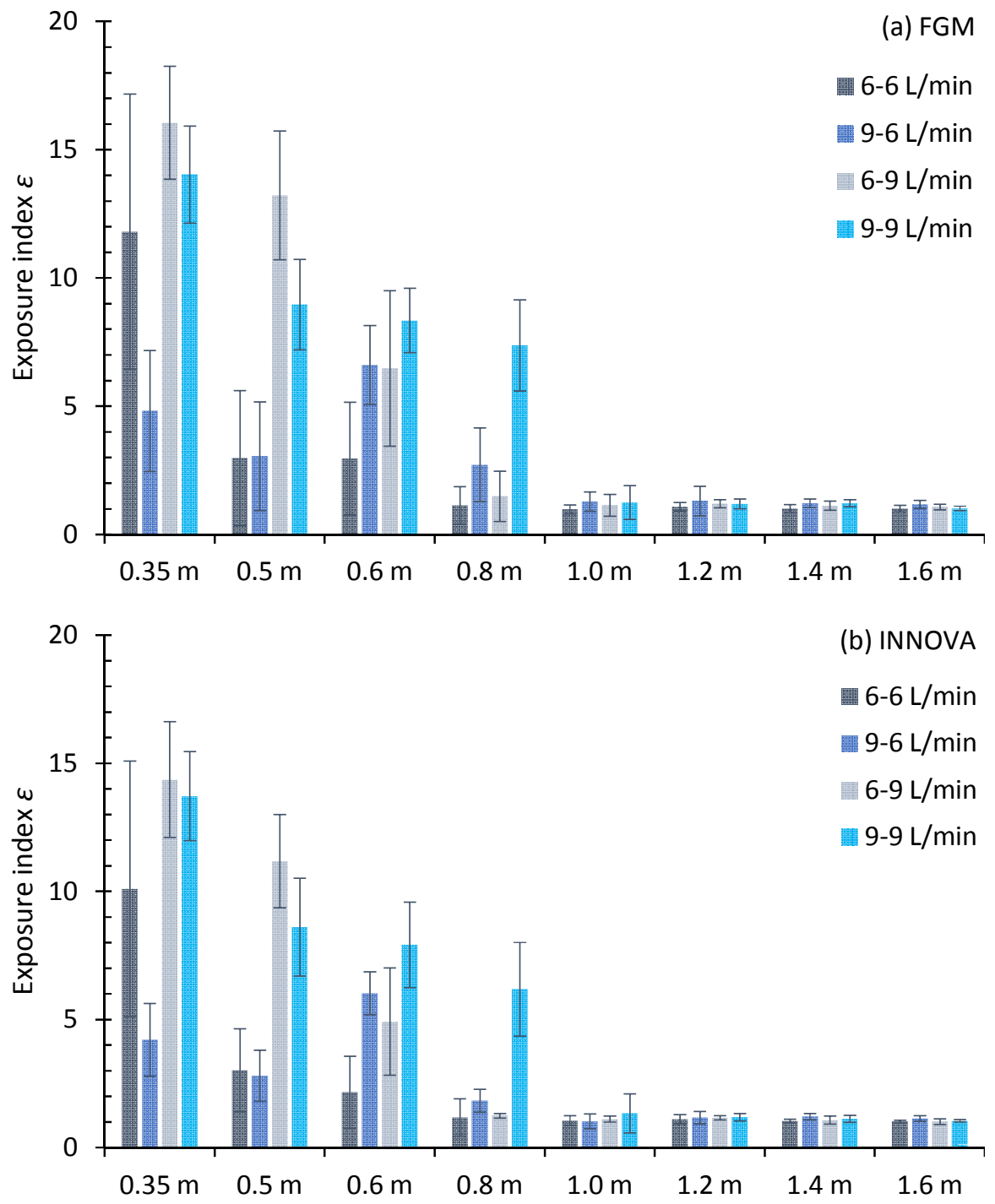

Figure 8 Influence of the pulmonary ventilation rate of infected and exposed persons on the exposure index at different separation distances under steady-state condition.

This article is protected by copyright. All rights reserved. 


\subsubsection{Influence of breathing cycle period}

Figure 9 shows the influence of the breathing cycle period of the infected and exposed persons on the exposure index of the exposed person. As for the influence of pulmonary ventilation rate, the influence of breathing cycle period on the exposure index extended only up to a separation distance of $1.0 \mathrm{~m}$. Compared to the breathing cycle period of $2.5-2.5-1 \mathrm{~s}$ that has been widely used in past studies, a decrease of breathing cycle period resulted in an increase in the exposure index. This increase was especially notable at the distances of 0.5 and $0.6 \mathrm{~m}$ when the breathing cycles were 2-2-0.8 $\mathrm{s}$ and 1.5-1.5-0.6 $\mathrm{s}$.

The time-averaged volume of the exhaled airflows for all these four cases with different breathing cycle periods were the same, which means that the time-averaged concentrations in the ventilation exhaust airflow from the room were the same for the four cases. According to the definition of the exposure index (see Equation (1)), the only difference between the four cases that could have caused the difference in the exposure index is therefore the timeaveraged concentration in the inhaled airflow of the exposed person. It can be seen that the influence of breathing cycle period on this time-averaged concentration was complicated, distance dependent and nonlinear with the change of breathing cycle period, and this is discussed in detail in Section 4.

This article is protected by copyright. All rights reserved. 

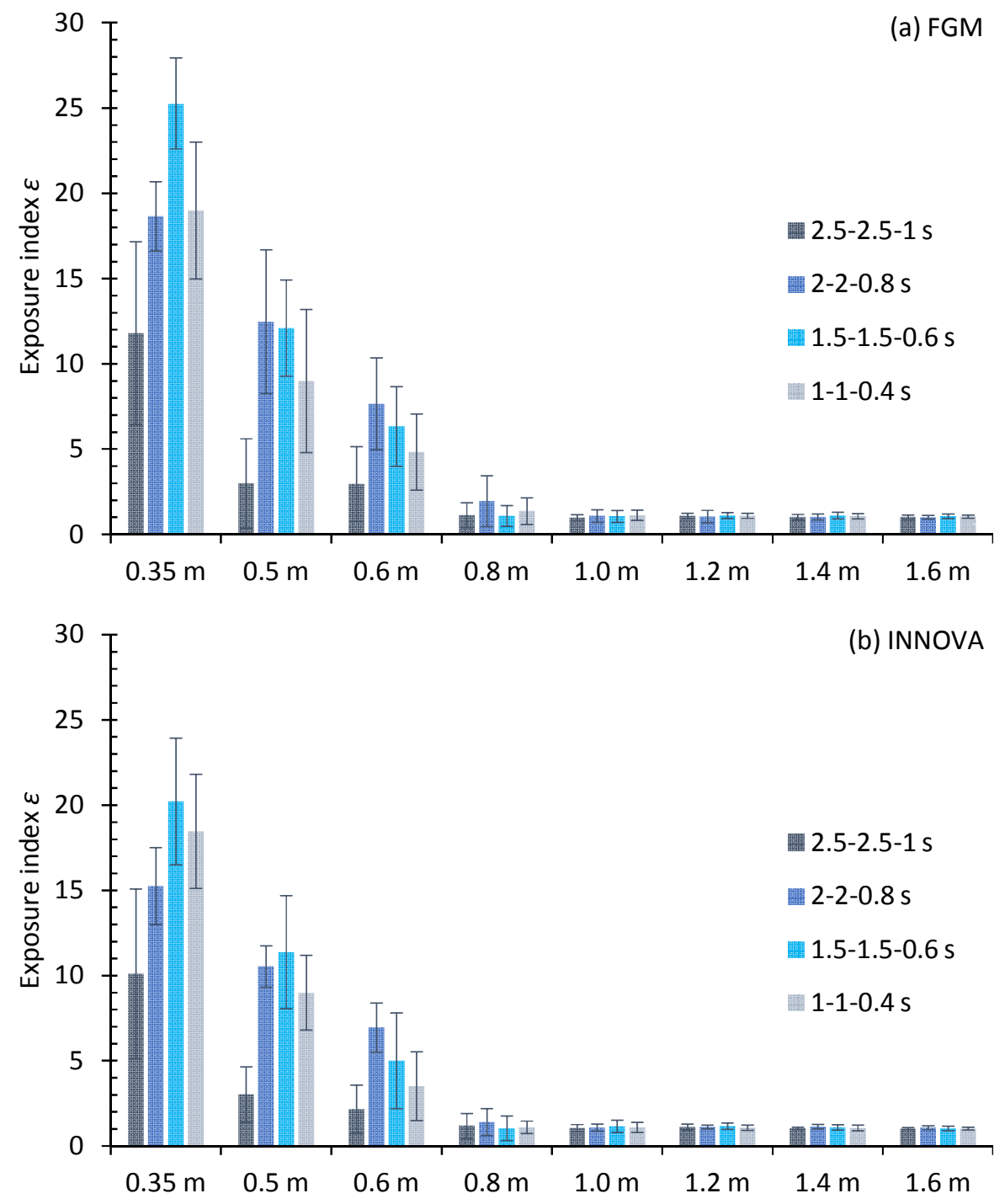

Figure 9 Influence of the breathing cycle period of infected and exposed persons on the exposure index at different separation distances under steady-state conditions.

\section{Discussions}

The results of the present study confirm that there are large variations in both peak exhaled airflow velocity and breathing cycle period between different human subjects; the results also revealed large differences between the averaged values obtained from the human subjects and the breathing manikins in terms of their peak exhaled airflow velocity and their breathing cycle period. Compared to human subjects, the manikin had a higher average peak exhaled airflow velocity and a longer breathing cycle period. A previous study by $\mathrm{Xu}$ and This article is protected by copyright. All rights reserved. 
colleagues $^{24}$ reported that human breathing is more complicated than has been simulated by a manikin in terms of airflow fluctuations, individual differences and exhaled flow directions. They also pointed out that the oversimplification of a manikins' mouth structure could result in a higher exhaled airflow velocity and a higher exhaled concentration. According to the results of the present study, the use of a higher exhaled airflow velocity would overestimate the risk of cross infection, while the use of a longer breathing cycle period would underestimate the risk of cross infection. In addition, the use of a higher exhaled concentration would certainly overestimate the risk of cross infection. The overall effect of these three aspects on the risk of cross infection depends on the differences in exhaled flow speed, breathing cycle period and exhaled concentration between the manikins used in the simulation and the subjects. In order to achieve a better simulation of human exhalation and thus more accurately assess the risk of cross infection, it is recommended that the initial flow distribution at the mouth should be more realistic and the breathing cycle period of manikins should be selected to be similar to that of the target subjects (seated or standing persons, office workers or audiences in sport stadiums, etc.).

The results of the present study show that subjects have slightly higher exhaled airflow velocities (and thus pulmonary ventilation rates) and lower breathing cycle periods while standing than while sitting. It was also found that increasing the pulmonary ventilation rate and decreasing the breathing cycle period of an exposed person resulted in a higher risk of cross infection. A combination of these two sets of results indicates that, under the same conditions, the risk of cross infection while standing is higher than while sitting. In addition, the convective boundary layer of the human body, even at the breathing zone, is thinner and weaker (has a lower upward velocity) while standing than while sitting. ${ }^{51}$ A thinner and weaker convective boundary layer is more easily penetrated by the exhaled flow and thus

This article is protected by copyright. All rights reserved. 
provides a lower level of protection from exposure. There are many places where people might either stand or sit, such as hospital wards, buses and trains. The findings of this study suggest that new control measures should be developed and implemented to either limit the spread of the air exhaled from supine or seated persons to the breathing level of standing persons or to provide clean air directly to the breathing zone of standing persons.

The results of the present study also show that, under the experimental conditions examined, the influence of breathing pattern on the risk of cross infection extended only up to $1.0 \mathrm{~m}$ in separation distance between the infected and the exposed person. This distance is in agreement with the threshold distance suggested in past studies ${ }^{10,52}$ when distinguishing between short-range and long-range cross infection. In general, short-range cross infection occurs when the infected and the exposed persons are located so closely that the breathing flow jets can approach each other's breathing zone. The risk of cross infection decreases sharply with an increase in separation distance until it reaches a threshold distance, beyond which the risk is determined mainly by the background concentration of the room air (longrange cross infection). Previous studies $5,6,53,10,16,54,55$ suggested different threshold distances ranging from $0.8 \mathrm{~m}$ to $1.5 \mathrm{~m}$ under different boundary conditions. Within the threshold distance, the level of risk of cross infection is increased both by direct exhalation from the infected person and by the background concentration. ${ }^{52}$ In this context, the findings from this study imply that improved and more accurate control measures for short-range cross infection should be formulated according to the breathing characteristics of occupants. Note that different observations could be obtained with stratum ventilation that has a strong supply jet flow across the breathing zone (see references ${ }^{56-57}$ ).

This article is protected by copyright. All rights reserved. 
The present findings show that increasing the pulmonary ventilation rate of an exposed person considerably increases the risk of cross infection. There are two possible reasons for this. First, a larger exhaled flow rate (from the nostrils) of the exposed person increases the low-pressure recirculation between the exhaled flow jet and the human body, which entrains more flows into the breathing zone and in turn results in a higher exposure index at the mouth (in the inhaled airflow). Second, a larger inhaled flow rate of the exposed person reduces the stagnation and separation of the exhaled flow jet from the infected person in the breathing zone of the exposed person and increases the penetration of this exhaled airflow jet into the free convection flow and thus the concentrations in inhaled air. The places where people usually have a higher pulmonary ventilation rate (due to a higher metabolic rate) include sports centres, sports stadiums, and theatre and cinema auditoriums. The present study suggests that these places should be included in any high-risk list and that improved control measures, such as an increased fresh air supply, are required.

The present study shows that compared to the widely used $6 \mathrm{~s}$ breathing cycle period, decreasing the breathing cycle period of both infected and exposed persons considerably increases the risk of cross infection. This is probably because a change of breathing cycle period modifies the flow interactions in the breathing zone by changing: (a) the mixing intensity between the exhaled flow jets and room air, (b) the penetration of the exhaled flow jets to the convective boundary layer around human body, (c) the length of time for which the exhaled flow of the infected person remains in the breathing zone of the exposed person, and (d) the dilution and scouring effect of the exhaled airflow of the exposed person. However, further studies using more advanced measurement techniques, such as Schlieren imaging or Particle Image Velocimetry (PIV), will be required to provide detailed explanations for the observed phenomena.

This article is protected by copyright. All rights reserved. 
Table 3 Average resting respiratory rate and breathing cycle period by age. ${ }^{34-37}$

\begin{tabular}{lll}
\hline Age & Respiratory rate [time/min] & Breathing cycle period $[\mathrm{s}]$ \\
\hline New born & $30-60$ & $1.0-2.0$ \\
Infant & $30-40$ & $1.5-2.0$ \\
An infant & $20-30$ & $2.0-3.0$ \\
School child & $18-25$ & $2.4-3.3$ \\
Adult & $12-18$ & $3.3-5.0$ \\
65 to 79 & $12-28$ & $2.1-5.0$ \\
Over 80 & $10-30$ & $2.0-6.0$ \\
\hline
\end{tabular}

The present study has several limitations. The purpose of the human subject test was to preliminarily explore the variations in breathing pattern between persons and between actual persons and 'the standard person' represented by a breathing thermal manikin. Extensive tests with more subjects are required to provide more representative and statistically stable information on these variations, especially between different groups of people, for example, at different activity levels and of different ages. The influence of the pulmonary ventilation rate and breathing cycle period on the risk of cross infection was examined systematically, but the findings were obtained under very specific boundary conditions: face-to-face positioning and no movement of the manikins. Further experiments under different boundary conditions should be conducted. The geometry and heat load of the thermal manikins used in the present study represent only adults and office working conditions. As children and elderly people usually have shorter breathing cycle periods than adults performing office work (see Table 3), further studies focusing on children and elderly people are required.

\section{Conclusions}

The results obtained in human subject measurements and in breathing thermal manikin experiments lead to the following conclusions.

This article is protected by copyright. All rights reserved. 
○ Both peak velocity of exhalation and breathing cycle period varied considerably between different subjects, and are very different from those that have been widely selected for use in breathing thermal manikins.

$\circ$ The area-averaged exhaled airflow velocity at $1 \mathrm{~cm}$ from the mouths of the five human subjects ranged from 0.61 to $1.6 \mathrm{~m} / \mathrm{s}$.

o The average breathing cycle period for mouth exhalation from the five human subjects ranged from 2.1 to $3.5 \mathrm{~s}$ when standing, which was on average $18.9 \%$ lower than when seated.

○ The pulmonary ventilation rate had a considerable influence on the exposure index when the separation distance of the simulated infected and the exposed persons was less than 1.0 m. Increasing the pulmonary ventilation rate of the exposed person considerably increased the risk of cross infection.

o The influence of breathing cycle period on the risk of cross infection extended only up to $1.0 \mathrm{~m}$ between the infected and exposed persons. Compared to the breathing cycle of 2.52.5-1 s, a decrease of breathing cycle period resulted in an increase in the exposure index. This, however, does not mean that the risk of cross infection always increases with a decrease of breathing cycle period.

o Under the same conditions, a standing posture resulted in a higher risk of cross infection than was observed for a sitting posture.

\section{Acknowledgements}

The authors would like to thank the human subjects who participated in the experiments. The research leading to these results has received funding from the People Programme (Marie Curie Actions) of the European Union's Seventh Framework Programme (FP7/20072013) under REA grant agreement no. 609405 (COFUNDPostdocDTU). Zhengtao Ai is a recipient of a Marie Curie Fellowship. It is declared that none of the authors have a conflict of interest. The authors would like to thank their colleague Prof. David Wyon for his professional English language editing and technical suggestions.

This article is protected by copyright. All rights reserved. 


\section{References}

1. Centers for Disease Control and Prevention (CDC). Diseases \& Conditions. Atlanta, GA: U.S. Department of Health and Human Services available at: https://www.cdc.gov/DiseasesConditions, accessed on April 09, 2017.

2. Ai ZT, Melikov AK. Airborne spread of expiratory droplet nuclei between the occupants of indoor environments: A review. Indoor Air. 2018; 28(4): 500-524.

3. Villafruela JM, Olmedo I, San Jose JF. Influence of human breathing modes on airborne cross infection risk. Build Environ. 2016; 106: 340-351.

4. Nielsen PV, Olmedo I, Ruiz de Adana M, et al. Airborne cross infection risk between two people standing in surroundings with a vertical temperature gradient. HVAC\&R Res. 2012; 18(4): 552-561.

5. Olmedo I, Nielsen PV, Ruiz de Adana M, Jensen RL. The risk of airborne cross infection in a room with vertical low-velocity ventilation. Indoor Air. 2013; 23: 62-73.

6. Olmedo I, Nielsen PV, Ruiz de Adana M, et al. Distribution of exhaled contaminants and personal exposure in a room using three different air distribution strategies. Indoor Air. 2012; 22: 64-76.

7. Cermak R, Melikov AK, Forejt L, Kovar O. Performance of personalized ventilation in conjunction with mixing and displacement ventilation. HVAC\&R Res. 2006; 12(2): 295311.

8. Gupta JK, Lin C, Chen Q. Characterizing exhaled airflow from breathing and talking. Indoor Air. 2010; 20: 31-39.

9. Altman PL, Dittmer DS. Respiration and Circulation, Bethesda, Maryland, Federation of American Societies for Experimental Biology, 1971.

10. Liu L, Li Y, Nielsen PV, et al. Short-range airborne transmission of expiratory droplets between two people. Indoor Air. 2016; 27(2): 452-462.

11. Yang J, Sekhar C, Cheong DKW, Raphael B. A time-based analysis of the personalized exhaust system for airborne infection control in healthcare settings. Sci Technol Built En. 2015; 21: 172-178.

12. Melikov AK, Dzhartov V. Advanced air distribution for minimizing airborne cross infection in aircraft cabins. HVAC\&R Res. 2013; 19: 926-933.

13. Li X, Niu J, Gao N. Spatial distribution of human respiratory droplet residuals and exposure risk for the co-occupant under different ventilation methods. HVAC\&R Res. 2011; 17(4): 432-445.

14. Sze To GN, Wan MP, Chao CYH, et al. A methodology for estimating airborne virus exposures in indoor environments using the spatial distribution of expiratory aerosols and virus viability characteristics. Indoor Air. 2008; 18: 425-438.

15. Dygert RK, Dang TQ. Mitigation of cross-contamination in an aircraft cabin via localized exhaust. Build Environ. 2010; 45(9): 2015-2026.

This article is protected by copyright. All rights reserved. 
16. Nielsen PV, Li Y, Buus M, Winther FV. Risk of cross infection in a hospital ward with downward ventilation. Build Environ. 2010; 45: 2008-2014.

17. Pantelic J, Sze To GN, Tham KW, et al. Personalized ventilation as a control measure for airborne transmissible disease spread. J R Soc Interface. 2009; 6: S715-726.

18. Qian H, Li Y, Nielsen P, Hyldgaard CE. Dispersion of exhalation pollutants in a two-bed hospital ward with a downward ventilation system. Build Environ. 2008; 43: 344-354.

19. Cao G, Liu S, Boor BE, Novoselac A. Characterizing the dynamic interactions and exposure implications of a particle-laden cough jet with different room airflow regimes produced by low and high momentum jets. Aerosol Air Qual Res. 2015; 15: 1955-1966.

20. Cermak R, Melikov AK. Protection of occupants from exhaled infectious agents and floor material emissions in rooms with personalized and underfloor ventilation. HVAC\&R Res. 2007; 13(1): 23-38.

21. Gao NP, Niu JL. Transient CFD simulation of the respiration process and inter-person exposure assessment. Build Environ. 2006; 41: 1214-1222.

22. Bjørn E, Nielsen PV. Dispersal of exhaled air and personal exposure in displacement ventilated rooms. Indoor Air. 2002; 12: 147-164.

23. Yang C, Yang X, Zhao B. Person to person droplets transmission characteristics in unidirectional ventilated protective isolation room: The impact of initial droplet size. Build Simul. 2016; 9: 597-606.

24. Xu C, Nielsen PV, Gong G, et al. Measuring the exhaled breath of a manikin and human subjects. Indoor Air. 2015; 25: 188-197.

25. Nielsen PV, Polak M, Jiang H, et al. Protection against cross infection in hospital beds with integrated personalized ventilation. Proceedings of Indoor Air 2008, Copenhagen, Denmark, August 17-22, 2008.

26. Melikov AK. Human body micro-environment: The benefits of controlling airflow interaction. Build Environ. 2015; 91: 70-77.

27. Haselton FR, Sperandio PGN. Convective exchange between the nose and the atmosphere. J Appl Physiol. 1988; 64(6): 2575-2581.

28. Tang JW, Nicolle AD, Klettner CA, et al. Airflow dynamics of human jets: sneezing and breathing - potential sources of infectious aerosols. PloS One. 2013; 8(4): e59970.

29. Xie X, Li Y, Sun H, Liu L. Exhaled droplets due to talking and coughing. $J R$ Soc Interface. 2009; 6: S703-714.

30. Bolashikov ZD, Barova M, Melikov AK. Wearable personal exhaust ventilation: improved IAQ and reduced exposure to air exhaled from a sick doctor. Sci Technol Built En. 2015; 21: 1117-1125.

31. Lipczynska A, Kaczmarczyk J, Melikov AK. Thermal environment and air quality in office with personalized ventilation combined with chilled ceiling. Build Environ. 2015; 92: 603-614.

32. Nielsen PV. Fifty years of CFD for room air distribution. Build Environ. 2015; 91: 78-90.

33. ASHRAE Handbook. Thermal Comfort. ASHRAE Handbook of Fundamentals 9.1-9.6.

This article is protected by copyright. All rights reserved. 
Atlanta, GA, American Society of Heating, Refrigerating and Air Conditioning Engineers. 2013.

34. Barrett K, Brooks H, Boitano S, Barman S. Ganong's Review of Medical Physiology (24 ${ }^{\text {th }}$ Edition). The McGraw-Hill Companies, Inc., US. 2012. ISBN 978-0-07-160568-7. Page 619.

35. Scott L, DeBoer RN. Emergency Newborn Care. Trafford Publishing LtD, UK. 2004. ISBN 978-1-4120-3089-2. Page 30.

36. Lindh WQ, Pooler M, Tamparo C, Dahl BM, Morris JA. Delmar's Comprehensive Medical Assisting: Administrative and Clinical Competencies. Cengage Learning. 2009. ISBN 978-1-4354-1914-8. Page 573.

37. Rodriguez-Molinero A, Narvaiza L, Ruiz J, Galvez-Barron C. Normal respiratory rate and peripheral blood oxygen saturation in the elderly population. J Am Geriatr Soc. 2013; 61(12): 2238-2240.

38. Melikov AK, Kaczmarczyk J. Measurement and prediction of indoor air quality using a breathing thermal manikin. Indoor Air. 2007; 17: 50-59.

39. Hoppe P. Temperatures of expired air under varying climatic conditions. Int J Biometeor. $1981 ; 25(2): 127-132$.

40. Grymer LF, Helberg O, Pedersen OF, Rasmussen TR. Acoustic rhinometry: values from adults with subjective normal nasal patency. Rhinology. 1991; 29: 35-47.

41. Melikov AK. Breathing thermal manikins for indoor environment assessment: important characteristics and requirements. Eur J Appl Physiol. 2004; 92: 710-713.

42. Benchetrit G. Breathing pattern in humans: diversity and individuality. Respir Physiol. 122 (2000) 123-129.

43. Kierat W, Popiolek Z. Dynamic properties of fast gas concentration meter with nondispersive infrared detector. Measurement 95 (2017) 149-155.

44. Kierat W, Popiolek Z. Methods of the gas concentration sinusoidal and step changes generation for dynamic properties of gas concentration meters testing. Measurement 88 (2016) 131-136.

45. Pantelic J, Tham KW. Adequacy of air change rate as the sole indicator of an air distribution system's effectiveness to mitigate airborne infectious disease transmission caused by a cough release in the room with overhead mixing ventilation: a case study. HVAC\&R Res. 2013; 19: 947-961.

46. Sze To GN, Wan MP, Chao CYH, et al. Experimental study of dispersion and deposition of expiratory aerosols in aircraft cabins and impact on infectious disease transmission. Aerosol Sci Technol. 2009; 43: 466-485.

47. Qian H, Li Y. Removal of exhaled particles by ventilation and deposition in a multibed airborne infection isolation room. Indoor Air. 2010; 20: 284-297.

48. Rim D, Novoselac A. Transport of particulate and gaseous pollutants in the vicinity of a human body. Build Environ. 2009; 44: 1840-1849.

This article is protected by copyright. All rights reserved. 
49. Zhu SW, Kato S, Yang JH. Study on transport characteristics of saliva droplets produced by coughing in a calm indoor environment. Build Environ. 2006; 41: 1691-1702.

50. Gao NP, Niu JL. Modeling particle dispersion and deposition in indoor environments. Atmos Environ. 2007; 41: 3862-3876.

51. Licina D, Pantelic J, Melikov A, Sekhar C, Tham KW. Experimental investigation of the human convective boundary layer in a quiescent indoor environment. Build Environ. 2014; 75: 79-91.

52. Nielsen PV, Winther FV, Buus M, Thilageswaran, M. Contaminant flow in the microenvironment between people under different ventilation conditions. ASHRAE Trans. 2008; 114(2): 632-638.

53. Bjørn E, Nielsen PV. Dispersal of exhaled air and personal exposure in displacement ventilated rooms. Indoor Air. 2002; 12: 147-164.

54. Melikov AK, Bolashikov ZD, Kostadinov K, et al. Exposure of health care workers and occupants to coughed air in a hospital room with displacement air distribution: impact of ventilation rate and distance from coughing patient. 10th International Conference on Healthy Buildings, Brisbane, Australia, 2012.

55. Bolashikov ZD, Melikov AK, Kierat W, et al. Exposure of health care workers and occupants to coughed airborne pathogens in a double-bed hospital patient room with overhead mixing ventilation. HVAC\&R Res. 2012; 18(4): 602-615.

56. Ai ZT, Huang T, Melikov AK. Airborne transmission of exhaled droplet nuclei between occupants in a room with horizontal air distribution. Build Environ. 2019; under review.

57. Lin Z, Wang J, Yao T, Chow TT. Investigation into anti-airborne infection performance of stratum ventilation. Build Environ. 2012; 54: 29-38.

This article is protected by copyright. All rights reserved. 